\title{
Exploring Monitoring, Work Environment and Flexibility as Predictors of Job Satisfaction within Australian Call Centres
}

\author{
John Annakis \\ Faculty of Business and Enterprise, Swinburne University of Technology \\ Melbourne, Australia \\ Antonio Lobo \\ Faculty of Business and Enterprise, Swinburne University of Technology \\ Melbourne, Australia
}

Soma Pillay (Corresponding author)

Faculty of Business and Enterprise, Swinburne University of Technology, Melbourne, Australia

P O Box 218, Hawthorn, Vic 3122, Australia

Tel: 61-3-9214-8536 E-mail: sopillay@swin.edu.au

Received: February 16, 2011 Accepted: March 5, 2011 doi:10.5539/ijbm.v6n8p75

\begin{abstract}
The purpose of this paper is to investigate predictors of workers' job satisfaction from the labour process and equity theoretical perspectives. The study employed a qualitative approach and draws on data from in depth focus groups of customer service representatives (CSR). The sample for this study was drawn from three Australian call centres operating in a variety of business sectors. The study highlights that three dimensions: monitoring, flexibility and work environment are significantly correlated to CSR job satisfaction. Developing an understanding of these dimensions is critical to understanding CSR job satisfaction perceptions in an industry which exhibits high labour turnover and absenteeism. This study provides new insights on how to manage effectively job satisfaction within call centre environments through the incorporation of more multi-dimensional aspects that are considered to be strong determinants of CSR job satisfaction. The study contributes to the literature by investigating a more multi-dimensional approach to studying job satisfaction in call centre environments. The intensive case study approach highlights the implications for HRM.
\end{abstract}

Keywords: Call centre, Job satisfaction, Australia, Monitoring, Work environment, Flexibility

\section{Introduction}

Call centres' juggling game to deliver efficient and standardized services while delivering a quality customer service is often a challenging one. Highly routinised cost saving control of the labour process tends to be incompatible with the non-standardised demands of customers. Customer requirements cannot be easily standardized; workers will require some degree of flexibility and discretion in negotiating their interactions with customers (Deery \& Kinnie 2004). However, not everyone considers call centres to be 'satanic mills' or 'modern day sweatshops'. Quite the opposite - management executives and government organisations have described them as enlightened workplaces of the future, offering job opportunities to semi-skilled and low-skilled workers (Taylor \& Bain 1999).

In order to determine how workers derived wellbeing and job satisfaction, this paper draws from labour process and equity theorists. Among the first group, Braverman (1974), Edwards (1990) and Fernie and Metcalf (1998) argue that employers and employees often have conflicting interests within the workplace. This conflict involves the control of the labour process, and shapes employees' work experience and attitudes to work commitment and effort. The second group formed by equity theorists assess employees' perception of fairness and equity from an internal and external perspective of management control practices including procedural justice and distributive justice (Blader \& Tyler 2003; Folger 1987; Leventhal 1980). Both perspectives are closely related. This study adopts a qualitative approach to exploring the way employees respond to the managerial control process which directly influences job satisfaction. We use the cases of three diverse call centre environments.

\section{The Case of three Australian Call Centres}

The geographical scope of this study was limited to one large city in Australia. The sample is consistent with the call centre's profile in Australia. It included a small, medium and a large organization across industries and sectors. 
The participating organizations demanded anonymity and confidentiality as a requisite to engage in the research. The researchers created the following pseudonyms for each:

- a bank which also offers superannuation funds to its members - Superco;

- a government service - Legalco;

○ a national market research firm - Researchco.

\subsection{Superco}

Superco is owned by several Australian superannuation funds. Established in 1994 to provide access to low cost financial products and services, since acquiring banking licence in July 2001 it has provided members with over $\mathrm{A} \$ 12$ billion in low cost home loans. Superco raises funds by issuing bonds and mortgage backed securities that are rated AAA or equivalent by Standard \& Poor's and Moody's Investors Service, and is regulated by the Australian Securities and Investment Commission (ASIC).

Superco's aim is to meet the basic financial needs of Australians by providing simple products with very competitive interest rates, minimal fees and no gimmicks. Technology is the key to providing these low cost financial products. There is no retail branch network but customers can use the phone, Internet, ATM, EFTPOS and Bank@Post ${ }^{\mathrm{TM}}$ interfaces to make transactions. The savings generated by this technology driven approach are passed on to customers through competitive interest rates, increased functionality, service and fewer charges. Superco employs over 600 staff, with offices in all state capital cities.

The call centre in Melbourne houses approximately 30 staff who handle member enquiries and give advice on renewals and new services. The call centre manager stated:

Unions are welcomed in the call centre and are often consulted with on most matters including the monitoring of calls ... All staff are invited to join the union upon induction into the company ... Our staff are encouraged to discuss and invited to be involved in day to day or any matters ... We believe it helps our organisation service our clients/members better.

The organisation promoted fairness and equity and participation, with workers made to feel that they were assisting clients who are members of superannuation funds which are also managed by trade unions. This was part of the cultural message transmitted through their policies, induction and ongoing training, and CSRs used it in their day to day language (servicing members).

\subsection{Legalco}

Legalco handles over 350,000 calls per annum, with 20 full-time and four part-time staff in its Melbourne call centre. This equates to an average of 60 calls per day for each CSR. Legalco is concerned less with time and more with service quality. This philosophy contrasts to that of the other call centres (with the exception of Superco) who all set time and sales targets.

Legalco is part of a federal government department and has seen several governments come and go. Restructuring has occurred mainly due to changes in industrial relations laws. During the previous federal Labor government, the organisation tripled its workforce. With the election of the Coalition government, Legalco underwent a complete restructure and became a smaller unit, transformed to emulate a call centre environment. Former staff were redeployed into other departments and new, younger and more university educated staff were recruited. To some extent it still exhibits a public service type culture in that it is part of a larger public service organisation.

The level of expert knowledge required is higher than in most other call centres investigated, adding variety and complexity to the CSRs' role. They are required at times to answer complex questions as well as provide advice on industrial relations and para-legal matters, check databases and compose and send email advice to enquiries or complaints to the public. Despite working in a call centre environment, they did not consider themselves call centre employees, but were referred to as 'professional advisors' who helped the community and worked for the public service. The call centre manager stated:

Our advisors belong to the whole department as their work role goes beyond just working on the phones all day ... They at times undertake face-to-face interviews with clients as well as liaise with legal and compliance staff ... very challenging but rewarding ... It is interesting that staff in other departments belong to the same organisation but consider themselves separate to call centre advisors ... Our call centre operation is sometimes seen by others in the organisation as a busy, exhausting and often stressful place to work in ... We rarely get staff moving across into our area, most of our new recruits are from outside of the organisation.

Legalco CSRs take calls on matters including pay advice, staff dismissal and sexual harassment. The service is free to the public so callers have high expectations to resolve often difficult problems. CSRs have some pressure to complete calls, however providing accurate, quality advice is more important according to the manager. Average call lengths were understandably longer for this organisation due to the complexity of the calls it receives. In terms of monitoring, all calls are taped upon consultation with unions and CSRs, and are generally monitored for quality, legal and quality assurance reasons. 
Legalco's manager commented on her memories of being a team leader and how it felt to be consistently monitored and asked to put in and meet quantitative statistical targets:

I would prefer to hand over the monitoring work to advisors as it is less intrusive, it tends to encourage trust ... It would then allow team leaders to do more interesting work like HRM, training, IT and project work where they can utilise their skills better. The advisors are capable of monitoring their own work, it gives them more control over the process and frees team leaders up ... I have to admit though that my present role entails a lot of monitoring of quantitative data and little emphasis is placed on quality of data and workers' performance ... At the end of the day, as long as our 'grades of service' are being met (minimum 300,000 calls per annum on our current budget), the organisation runs smoothly ... that's what matters.

\subsection{Researchco}

Researchco is a small market research consultancy operating nationally from Melbourne and Sydney. The call centre observed in this study operated in the eastern suburbs Melbourne and consisted of 60 casual staff, including others on demand. According to the operations manager, staff was often recruited from a local university due to their reliability and people skills, together with the multitude of languages spoken by students. Researchco surveys respondents in 40 countries in 16 languages. Clients include six of Australia's 10 largest corporations and several more of the 50 biggest private and public sector enterprises. Last year, the organisation made over 1.4 million phone calls. Researchco conducts polls through newspapers, the internet and over the telephone, as well as face-to-face focus groups. It also employs nearly 400 field interviewers in Australia and hundreds more overseas. The sample surveyed in this study consisted of 24 CSRs who conducted market research over the telephone as their principal work

The CSRs at Researchco are all employed as casuals and most were also studying at Swinburne University. They saw the job as fitting in with university studies, which may explain why the average length of service is higher than any other case study organisation as. Seventy-two percent have been with the organisation for more than 19 months, however the operations manager stated staff turnover to be at $20 \%$ per annum. Hence some caution needs to prevail when interpreting the manager's reported turnover trends. As not all CSRs were given regular shifts, they could sit on a waiting list on an on-call basis. Workers are also constantly recruited and put on this on-call arrangement.

The management style is considered authoritarian in nature, and there is a hostile attitude towards unions. The pay structures are the lowest of all case study organisations, with employees paid the minimum award rate irrespective of output. They were not compensated for working late shifts and unsocial hours.

An 'us and them' management versus CSRs divide appeared evident, exhibiting signs of low trust for management who had long-term tenure, permanent and swishier offices as compared to hot-desking and casual on-call contracts for CSRs with little input into the process. This is highlighted in the following statements by the operations manager:

We need to juggle our clients' needs and meet strict costing and timing deadlines ... so rostering and getting interview staff can be difficult at times ... That's why we keep a bank of staff on call ... If staff aren't available we have a wider pool to draw from ... We try to look after the workers who are available at short notice by giving them more work. Also those who constantly make mistakes and have no attention to detail ... or keep making excuses about short notice just don't get any more work.

The manager argued against a unionised workforce, expressing his disgust at the Australian Services Union tactics of enlisting call centre workers by roping them into a federal award. The manager successfully contested the push by arguing that his workers were market researchers, not call centre workers, and were entitled to a different award.

\section{Conceptual Framework-The Predictors of Job Satisfaction Model}

The interview protocol comprised the PMS constructs such as (i) monitoring, (ii) flexibility, (iii) work environment, (iv) HRM and PMS, and (v) overall job satisfaction, and suggested changes to improve job satisfaction. These constructs were tentative and flexible allowing new research themes to emerge for theory building purposes.

\section{Insert Figure 1 here}

Figure 2 illustrates the details of the monitoring dimension and its nine items which were developed after careful consideration of the call centre literature. Overwhelmingly call centre researchers argue that the lower the level of monitoring, the reasonableness of the pace and the fairness of monitoring (in terms of links to rewards or punishment), the higher the level of CSR job satisfaction.(Deery, Iverson \& Walsh 2002; Holman 2002; Holman, Chissick \& Totterdell 2002; Mason et al. 2002; Rose \& Wright 2005). In particular the findings reveal commonalities as to the perceived effects of monitoring by concluding that increasing stress through pace of work, high targets and levels of monitoring and emotional pressure from customer interaction lead to stress and lower job satisfaction (Deery, Iverson \& Walsh 2002; Holman \& Fernie 2000; Rose \& Wright 2005; Smith et al. 1992). Chalykoff and Kochan (1989) also refer to CSRs' perceptions that it is an invasion of privacy, however most 
researchers fail to take up this distinction. Work related monitoring linked to PMS is expected to contribute to emotional exhaustion via repetition and via reducing functional flexibility (task discretion). It also leads to stress via fast pace, high volumes and what is being monitored for reward or punishment. Non-work-related monitoring is expected to lead to CSR stress as a possible invasion of personal privacy (intrusion into work-life balance) and indirectly to job withdrawal intentions rather than emotional exhaustion.

Other investigators have extended the scope of monitoring to cover how it relates to the privacy of workers as an invasion of privacy of non-work-related activities (Aiello 1993). Some have identified a gap in the literature, in particular the scarcity of empirical studies on workplace privacy (Lankshear et al. 2001; Lankshear \& Mason 2001), also the fact that monitoring can lead to increased stress and anxiety through being watched, at random or without consent (Nussbaum \& duRivage 1986). The questionnaire made this distinction to avoid ambiguities and establish a clear linkage to job satisfaction.

Due to the complexity of each dimension and their sub-categories each dimension is illustrated separately, but linked back to the overall model as depicted in Figure 1.

\section{First Dimension: Monitoring \\ Insert Figure 2 here \\ Work environment}

Drawing from the literature it can be argued that the most significant factors contributing to job satisfaction perceptions are those related to the work based environment (Deery, Iverson \& Walsh 2002; Holman 2002; Rose $\&$ Wright 2005). Yet the confines of what work based environment factors are and the way that they are defined tend to be inconsistent across the literature. Although the measures used by researchers vary somewhat their findings are consistent across call centre studies in different countries and industries.

Rose and Wright (2005) contend that CSRs' perception of involvement and consultation over work based context matters has a significant effect on job satisfaction. Those who perceived they were adequately consulted, informed of changes and involved in decision making (on day to day matters) exhibited less anxiety, stress and improved morale thus improving conditions of work leading to job satisfaction.

Attitudes towards this factor reflect consistently favourable or unfavourable responses to job satisfaction according to call centre studies and the general management literature. If this assumption is correct, one would expect that CSRs would put up with other factors such as monitoring, inflexibility, low benefits and poor HRM practices. However Hackman and Oldham (1975) contend this is not the case. They argue that the absence of control over these work based characteristics would lead significantly to worker dissatisfaction.

A common assumption made in both management literature and call centre research is that the more CSRs like or positively perceive work based environment factors, the more satisfied they are and the lower the stress or intention to leave the organisation (Deery, Iverson \& Walsh 2002; Frenkel et al. 1998; Holman 2002).

In the 2001 Special Eurobarometer 56.1 a sample of 6445 citizens aged 15 and over residing in EU-15, employed and self-employed were asked a number of questions relative to their job, including the degree of functional, numerical and time flexibility, and their job satisfaction. The study found that the greatest positive impact on both facets of job satisfaction is produced by employee involvement, and the positive effect is more pronounced when considering satisfaction relative to intrinsic aspects. opportunity to use own abilities, ability to use own initiative, chance to develop oneself, scope for innovation and creativity, work variety, possibility of achieving work targets, relations with manager and ability to contribute something useful to society (Origo \& Pagani, 2008).

While this is somewhat obvious, the importance of having this component in the study is to understand how it may or may not interconnect with, or perhaps may influence, other components of job satisfaction such as job retention and customer satisfaction.

\section{Insert Figure 3 here \\ Dimension: Flexibility}

CSRs' positive perception of flexible work practices would have a positive association to job satisfaction. A common hypothesis in the management literature (Hackman \& Lawler 1971; Hackman \& Oldham 1975) is that challenging and stimulating work is a motivator which contributes to job satisfaction.

Most researchers have referred to discretion and control over work task, including its variety and nature, as job control. The researcher decided to categorise this factor under functional flexibility for the purposes of clarity.

Drawing from the literature, one can assume that CSRs who are provided with adequate flexible work practices would be more satisfied on the job. Whether this is the case and what particular aspects of flexibility are important was a central point of investigation of this research.

\section{Insert Figure 4 here}

Figure 4 identifies some commonalities from the limited number of call centre research findings in relation to CSRs' perception of flexibility factors and links it to job satisfaction. Flexibility definitions, measures and 
consistency across call centre research are often quite disparate. Most call centre researchers apply task discretion or control over tasks (functional flexibility) as their underlying measure of flexibility (Deery, Iverson \& Walsh 2002; Frenkel et al. 1998; Holman 2002; Rose \& Wright 2005). Whilst others focus on temporal dimensions such as preferred hours, shifts and unsocial hours (Barnes 2005; Hyman et al. 2003), Reilly (2001) uses a more comprehensive measure of flexibility to include functional, numerical, temporal, locational and financial dimensions.

One of the most researched components of flexibility is functional flexibility which is often referred to as task flexibility or CSR control over variety of work tasks. CSRs who perceive low levels of control of this factor are often associated to lower levels of job satisfaction (Annakis \& Lasky 2004; Barnes 2005; Rose \& Wright 2005). Other factors that play an important role and that are specifically related to intrinsic job satisfaction are the work itself which includes variety, opportunity to use one's skills and autonomy (Deery, Iverson \& Walsh 2002; Frenkel et al. 1998; Holman 2002).

There has been very limited investigation of employee control over temporal flexibility, the choice over part-time, shifts, associated penalty rates during certain shifts, break times. Barnes (2005) identified that CSRs perceived low levels o control over temporal flexibility which contributed to stress and reduction of job satisfaction. Hyman et al. (2003) in reference to family and work-life balance matters and wellbeing found that CSRs perceived overall low degrees of influence over hours, shifts and the degree of influence of having to work overtime.

Reilly's (2001) investigation of a number of industries and occupations concluded through qualitative research that CSRs in particular experienced low levels of control compared to other occupations over numerical, functional, temporal, financial and locational flexibility factors. Where these factors existed they were only offered to managers, HR managers and technical staff, not to CSRs. Flexibility factors had little variation as prescribed by management and computerised systems such as ACD; whether to employ on a part-time, full-time or casual basis (numerical) was most of the time management driven. Temporal flexibility such as rostering of times and shifts were not normally negotiated with CSRs. Financial remuneration had some flexibility in terms of bonuses and commission but this was management driven. Location of work (locational flexibility) was restricted to the call centre workplace for CSRs. The researcher also considered other areas of flexibility emerging in the literature that may be important to CSRs' perception of job satisfaction.

There is a biased response from CSRs that the researcher has to calibrate. They may in fact expect low levels of other forms of flexibility as these working practices are common to industry and in particular to the their occupation. CSRs may not reflect these factors accurately in their own assessment of job satisfaction. Barnes (2005) reported this contradiction using mixed survey and interview approaches. When CSRs responded to closed questions related to flexibility in a questionnaire they placed little importance as to whether it impacted on their satisfaction or overall wellbeing. However when she used more in-depth qualitative approaches it was found that CSRs experienced low levels of control over temporal flexibility. This would contribute to stress levels and overall wellbeing. The only empirical avenue to determine which particular forms of flexibility are important to CSRs is to undertake more comprehensive research utilising wider measures (i.e. by incorporating the five elements of flexibility outlined above). Most of the few call centre studies which examined flexibility and its link to job satisfaction revealed functional flexibility (or task flexibility) and temporal flexibility as the most commonly reported measures (Barnes 2005; Hyman et al. 2003).

This research pursued this avenue by developing and testing wider measures of flexibility that are linked to common perceptions of CSRs' job satisfaction.

\section{Dimension: HRM and PMS}

The researcher identified a critical methodological issue in the call centre literature in relation to HRM and PMS factors. Of the limited studies that have investigated these factors there has been some disparity in the measures used (Deery, Iverson \& Walsh 2002; Frenkel et al. 1998; Holman 2002; Rose \& Wright 2005).

The elements of HR practices and performance management according to the literature can include the following:

- HR practices: payment and bonus, performance systems fairness and training;

- Extrinsic job satisfaction;

- How satisfied CSRs are with features external to the work itself (pay, opportunities for advancement, the way the firm is managed) (Holman 2002).

Chalykoff and Kochan (1989) investigated satisfaction with monitoring systems, including the amount of feedback received, the way in which it is shared, and its constructiveness and frequency. The monitoring system is closely related to the PMS as one is the process through which management applies the performance criteria (used by HR to reward or punish). These CSR perceptions, in terms of HR practices, could directly or indirectly impact on procedural fairness, pay and team morale and trust and overall perceptions of job satisfaction.

Holman (2002) developed measures to test intrinsic and extrinsic factors that could predict job satisfaction in call centres. Intrinsic job satisfaction used a seven-item Likert scale that asked about the extent to which CSRs are satisfied with features integral to the work itself (variety, opportunity to use one's skills, autonomy) $(\alpha=0.88)$. He 
also measured extrinsic job satisfaction using an eight-item Likert measure that asks about the extent to which CSRs are satisfied with features external to the work itself (pay, opportunities for advancement, the way the firm is managed) $(\alpha=0.80)$.

Holman (2002) found that the fairness of the payment system, the usefulness of performance appraisal and the adequacy of training tended to be associated negatively with depression and positively with extrinsic job satisfaction. In respect to performance appraisal, getting constructive feedback can be construed as a satisfying experience. His findings support previous non-call-centre research findings on this point (Grant, Higgins \& Irving 1988; Petrescu \& Simmons 2008). He also found that team leader support had a high positive association with wellbeing, and training may decrease CSRs' anxieties about ability to do the job. Holman (2002) concluded that similar to research on workplace characteristics and HRM practices, research was clearly lacking on employee response to intrinsic and extrinsic job benefits.

\section{Insert Figure 5 here \\ Dimension: Job benefits}

There has been limited investigation of job benefits and their link to job satisfaction. The few relevant studies identified and used measures that were not consistent. Rose and Wright (2005) suggest that pay and non-pay benefits may ameliorate the negative effects of other factors in the labour process and be indirectly linked to job satisfaction. Deery et al. (2002) found that job benefits related to pay, and non-pay matters such as social conditions; workstations, welfare and staff facilities contribute to morale, improve work-life balance and reduce stress leading to job satisfaction.

\section{Insert Figure 6 here \\ Job satisfaction}

This is the final construct of the conceptual model and constitutes CSRs' reaction to managerial control techniques. It is a collaboration of effects and responses of the preceding five constructs, and also allows the observation of job satisfaction effectiveness.

\section{The Study}

\subsection{Research Objective and hypothesis}

The main purpose of this research was to investigate the nature and extent of predictors of job satisfaction. This was done by studying CSRs in Australian call centres. We were especially interested in first, exploring the strength and direction of the relationship between the call centre job satisfaction dimensions (job related factors) (i)monitoring, (ii)flexibility, (iii)environment, (iv)HR policies/performance and (v)job benefits and second, identifying which call centre job satisfaction dimension/s best explain and predict job satisfaction. The following hypothesis were developed-

Hypothesis 1: Monitoring is directly and positively associated to job satisfaction

Hypothesis 2: Flexibility is directly and positively associated to job satisfaction

Hypothesis 3: Employees' control of environment is directly and positively associated to job satisfaction

Hypothesis 4: Performance management and HRM factors are positively associated to job satisfaction

Hypothesis 5: Job benefits are positively associated to job satisfaction

\subsection{Focus Groups}

Participants were recruited by way of a flyer distributed in the staff room and kitchen areas. Those who wished to participate contacted the researchers directly via telephone or email. Those who confirmed that they wished to participate were given either in person or by email a brief guide of ideas that would be discussed and a letter of informed consent that explained the purpose of the exercise and to also gain written and signatory permission for participants to join the focus group discussions.

In all, 3 focus group discussions took place with a total of 36 participants. Focus group methods provide direct and immediate evidence about similarities and differences in opinions and experiences as opposed to reaching such conclusions from post hoc analysis of separate statements derived from each interviewee (Cavana, Delahaye \& Sekaran 2001). The focus group participants were fairly representative of the community with a mixture of males and females, from various ethnicities, ages (22 to 65) and educational backgrounds. There were no known clusters amongst the participants, which assisted in avoiding any potential partiality or bias in responses. The selection of the sample was based on convenience and availability and was overall considered a fair and good combination. It was not necessary to be precise with the selection procedure because the exercise was really focused on generating thoughts and ideas regarding the nature of work in call centres and the research process.

\subsection{Focus group protocol and semi-structured interview questions}

Focus group guidelines were provided to the participants as a general guide only, however being a group discussion also allowed for free flow of conversation by participants (see Table 1). A case study protocol contained 
the instrument, procedure, and general rules to be followed during each interview. This is necessary to increase reliability and to guide the investigator in undertaking data collection (Yin 2003).

\section{Insert Table 1 here}

\section{Findings}

\subsection{Case study organisation 1: Superco}

In terms of the survey results Superco CSRs reported positively to all the dimensions except HRM and PMS where there was lack of training and career opportunities open to staff. Lack of functional flexibility in terms of repetitiveness and lack of variety was also raised by three CSRs in focus groups. Pay rises and benefits were a concern for some. CSRs were generally very satisfied with work and the qualitative findings suggest that they derive positive satisfaction through identifying with the external client.

\section{a) Monitoring and personal privacy}

The findings indicate that CSRs generally felt that monitoring was low and personal privacy high. It consulted CSRs and unions on the taping of calls, and unions were instrumental in intervening or resisting how the information would be used in performance management and appraisal. These reporting requirements influenced CSRs' perception that monitoring was a legitimate activity. High perceived levels of personal privacy can be explained by the fact that management permitted use of work facilities (internet, emails, phones) for non-work matters within reason.

\section{b) Work environment}

Focus group findings suggest positive attitudes to work environment and management changes, management dealing with problems and being involved in decisions that directly affect their work.

\section{c) Flexibility}

In terms of numerical and temporal flexibility Superco CSRs had positive perceptions but less so with other forms of flexibility (functional, locational and financial). They also exhibited positive attitudes to job benefits and social conditions of work.

Focus group discussions are consistent with these findings, other areas raised as concerns being poor pay, lack of career progression and training and development. Five CSRs suggested improving temporal and functional flexibility by having more regular and shorter breaks and job rotation and training to improve functional flexibility:

Working for this organisation ... you get along well (CSRS7) ... Management and team leaders are great and listen to us (CSRS8) ... Sometimes the work can get boring after a while. Job rotation or being released to undertake outside workshops and training could relieve the stress (CSRS9) ... More breaks and time to socialise between breaks could be good... I have been here a while but it is not a career job as you can't really move up the ladder there are only three levels ... Not getting along with certain agents, you can ask to change team (CSRD7).

Overall Superco CSRs felt rather positive to most of the dimensions that related to the nature of work. An emerging area from the focus groups related to positive identification with the client as a source of satisfaction. Six out of 12 felt positive about helping clients or members of the bank and superannuation funds they serviced. A close identification was found with the customer or member as referred to by CSRs. That, coupled with supportive managers, team leaders and managers, was one of the most positive aspects of the role.

\subsection{Case study organisation 2: Legalco}

Overall the results for Legalco showed that CSRs felt either positive to most aspects of the five dimensions and the focus group findings also confirm this, especially positive perceptions of work environment being a participative and consultative approach taken by management, also what emerged in the qualitative findings related to a positive and close identification with external clients they serviced (see Table 4, Appendix 2). Major concerns in focus groups related to lack of functional flexibility, such as repetition and monotony of task, also HRM and PMS, such as lack of pay rises, inadequate ongoing training and lack of career prospects.

\section{a) Monitoring and personal privacy}

Focus group discussions on monitoring and personal privacy confirm a neutral or generally positive attitude. CSRs perceived this as a legitimate part of the job as reinforced by management for client quality assurance purposes as a safeguard and protection for their clients:

I am monitored for giving advice (CSRL2) ... It is an accepted part of the job as we are often giving sensitive para-legal advice which could affect working lives (CSRL3) ... The advice we give has to be accurate (CSRL4).

These positive perceptions are identified by only two studies in the literature (Chalykoff \& Kochan 1989; Frenkel et al. 1998).

We are given freedom to make personal calls, emails and use the internet. As long as calls are answered it is considered acceptable (CSRL2) ... We have a staff room with facilities to use during scheduled breaks or when there are slack times on the phone (CSRL1) ... It hasn't been an issue around here as management are pretty 
understanding (CSRL4).

\section{b) Work environment}

The majority of the focus group respondents felt that the work environment was informed, problems were dealt with and CSRs were encouraged to be involved in decisions that affect their direct work role. In focus group discussions $42 \%$ responded positively that team leaders and management encouraged their input into decision making and participation in daily matters (see Table 4, Appendix 2).

Although teams are measured against each other to see who meets best performance on a weekly, monthly, quarterly basis, team leaders tend to cover for each other and compare standards before reports are due in to help each other meet targets across teams (CSRL8) ... This encourages trust for teams as we feel team leaders are supporting us and not just upping targets for senior management or forcing competition amongst teams (CSRL10).

\section{c) Flexibility}

Legalco CSRs generally felt satisfaction with numerical and temporal flexibility, however further analysis reveals low levels towards other flexibility factors especially functional flexibility. The lack of functional flexibility as reported by negative perceptions of repetition, boredom and lack of variety of task is the most commonly reported phenomenon in call centre literature.

\section{Functional flexibility}

When you start, you learn so much, giving advice is interesting and very challenging (CSRL8) ... After three months or so, once you learn the legislation and get experience with client calls, the job is no longer challenging (CSRL7) ... Often listening to the same issues and giving the same advice ... boredom sets in ... It gets rather repetitive ... I switch off at times (CSRL9) ... You come to realise that there is little scope to take on other tasks or duties (CSRL8).

What is consistent is that functional flexibility is a major concern for these CSRs after three months on the job. Despite the complexity of the nature of the job, repetition and boredom sets into the role and CSRs become rather dissatisfied. Lack of career development was highlighted in focus groups where some felt that their job was replaceable and that training and development was not a priority for long-term staff, just for new recruits, also they generally felt underpaid for the work they did. Lack of career progression was a concern for only a small number of CSRs. Those who raised these concerns in focus groups questions were from Legalco which was part of a larger government department. They would like to stay in the organisation and move up the ladder, but the call centre structure did not allow for this and there appeared to be a sense of built-in obsolescence not only in skill as reported earlier, but from a structural management perspective, where CSRs were constantly replaced with new ones. Training was intensive in the initial stage of around three months then became less of a priority for CSRs who may have felt overlooked and stagnant in their role over time. Job rotation and moving CSRs to other teams or helping them find jobs in other departments and in some cases outside the organisation was a strategy used at Legalco:

The problem is that this organisation is flat and there are no opportunities for advancement, only to team leader (CSRL10) ... People in other parts of the department such as compliance or policy often look at advisors here poorly and you are not considered for other department jobs unless you have undertaken further studies in law or IR (CSRL11) ... Advisors normally don't hack here long enough unless they go part-time ... Also there are new IBL students taken on every year for paid placements ... So it is hard to get pay rises, management can't justify promotions and pay rises, the new staff are doing the work for less pay (CSRL8).

This lack of career opportunities in a public service organisation was an interesting finding in that it highlighted feelings of role conflict for CSRs. This concern was expressed as contradictory to overall public service practices.

\section{Numerical flexibility}

The results overall revealed positive perceptions of numerical flexibility from the focus group findings discussions. However using focus group discussions helped explain some of the negative perceptions related to preferred contract status:

They only encourage part-time work if you are studying externally or can show you have family commitments, otherwise the only jobs here are full-time (CSRL1) ... Team leaders allow you time in lieu starting or finishing one hour earlier or later with little notice (CSRL3) ... But you are restricted by the office hours ... and of course call volumes at peak time (CSRL1) ... As calls are covered during peak time it is fine ... however a lot of clients ring between 12 to 1.30 , their lunchtimes, so it is hard to get a rostered break then especially for advisors (CSRL4) ... Team leaders don't seem to have that problem ... so it is difficult meeting friends or colleagues for lunch as most people don't do lunch before 12 or after 2 (CSRL5).

A theme emerging from focus group discussions but not covered in the the literature is that Legalco CSRs reported positive perceptions of their work culture, in particular close identification with external clients. The only reference to this identification ('social reference as a source of general life satisfaction') was in non-call-centre studies (Bryce \& Haworth 2003; Jahoda 1981, 1982).

Six of the 12 focus group participants referred to this as a major positive aspect of the job (see Appendix A19). 
CSRs enjoyed helping clients which could be interpreted as seeing themselves as 'good Samaritans' helping the public who experienced industrial relations problems. CSRs felt that they were often the last port of call for the public for their problems. The following verbatims highlight a sense of being needed by the client and identification with the clients:

At the end of the day, I enjoy helping clients solve problems, such as trying to recover lost wages or advising clients that they were underpaid (CSRL2) ... It is a satisfying feeling (CSRL1) ... Also getting employers ringing up who are trying to do the right thing by their employees (CSRL4) ... You are restricted at times by what advice you can give as some situations are touch and go, but generally knowing someone kept their job or improved their conditions of work as a result of your advice is the most important part of the job (CSRL3) ... Sometimes clients do go crazy and scream at you, it can be frustrating at times ... but once you realise they have been pushed around and passed on from one department, government agency, legal service to another ... and that they are genuinely grateful ... it makes the job worthwhile (CSRL6).

\subsection{Case study organisation 3: Researchco}

What was highlighted from focus group discussions is that the most negative comments related to poor work environment as a result of unfriendly and authoritarian management practices and lack of numerical and temporal flexibility, in particular lack of hours and/or lack of permanent or enough shifts. Unlike the other call centres, an emerging positive area was highlighted where CSRs derived satisfaction from work that wasn't challenging in task (lacking variety) as it fitted in well with other non-work commitments. Another area emerging from the focus groups and not reported in the literature is that most, being local students, had a positive identification with the team.

\section{a) Monitoring and personal privacy}

Researchco used random taping of calls without CSRs' consent and also used higher levels of quantitative monitoring than the other organisations. This was reflected in more negative attitudes to monitoring and personal privacy in focus group discussions.

\section{b) Work environment}

The responses to work environment highlighted that Researchco CSRs were very concerned with management practices, in particular very low levels of feeling informed of changes, being involved in decision making and feeling that management did not deal with problems effectively (see Table 2, Appendix 1).

The lack of team meetings and the authoritarian management style, including abuse by managers at meetings, were raised as concerns by eight out of 12 CSRs in focus groups. One stated that 'management keeps important things away from staff and they do not deal with any real issues especially at meetings' (see Table 3, Appendix 1):

Inconsistency of management in the way decisions are made is frustrating (CSRR1) ... Poor management practices in relation to work, shift rostering (CSRR2) ... Lack of respect, no communication and lack of opportunity for feedback (CSRR4) ... Supervisors and managers have poor communication skills, there is a 'culture of fear', there is no recognition for good work, they just highlight the negatives, they are very hands-off and unfriendly (CSRR9) ... What equality? Staff employed after me are treated better, they are getting more training options and better benefits (CSRR8).

Emerging from the qualitative findings is the identification with team as a source of job satisfaction. Some of the positive aspects of working at Researchco as highlighted in focus group discussions was that 10 out of 12 CSRs suggested that targets were realistic and there was no real pressure, it was easy work for an average pay. Five also commented that management allow them to pick shifts around your studies. Eight said that they enjoyed the team culture where most of the students working there became friends as they studied at the same university around the corner which made work more bearable and enjoyable as they had this in common.

Most of the work is easy (CSRR8) ... Getting enough hours and shifts can be a pain, and rostering (CSRR10) ... I enjoy working with people I study with at Swinburne, the rest of the crap annoys me ... but I can put up with it (CSRR4).

Built environment such as noise levels (no partitions) and hot-desking (sharing desks and equipment) was raised as a concern by three CSRs in focus group discussions. Being involved in outbound only operations where CSRs were required to contact customers and conduct interviews caused some pressure from abuse and rejections. Six CSRs disliked working to rigid scripts with customers as it felt contrived and a further four felt the intensity and volume of calls led to lack of variety and boredom at times. Because of the way work was structured there was no time to socialise and debrief, and they often felt isolated from other team members.

\section{c) Flexibility}

Overall Researchco CSRs were less than satisfied with flexible work practices (see Table 2, Appendix 1 ). However the focus group discussions also highlighted some attitudes towards functional flexibility which were of a more positive nature (see Table 4, Appendix 2). 


\section{Functional flexibility}

Emerging from the focus groups analysis was that functional flexibility was not a concern for CSRs. It was stated upfront by management that the work was easy and there was little scope for a career with the firm. Focus group discussions reveal that monotony and repetition was not a major concern, with only three out of 12 making reference to boredom or repetition, these had been with the company for over 18 months. Overall they felt happy undertaking an easy job to fit in with their studies as all of the CSRs were either full-time or part-time students. As long as they received their pay and suitable shifts, functional flexibility was not an issue for most CSRs. There were concerns with the lack of regular work and lack of socialisation, less so the lack of variety and poor management practices and communication.

\section{Numerical flexibility}

In terms of numerical flexibility or control over fixed working contracted hours Researchco CSRs felt lower levels of numerical flexibility as they often preferred full-time or part-time work rather than casual.

The individual case analysis provided qualitative insights about the degree and intensity of CSRs' feelings towards call centre management policies and practices The responses helped identify specific managerial practices to increase job satisfaction thus increasing productivity.

The individual call centre degree and intensity of responses is analysed in the next section in an aggregated form to put into context the significance at cross-call-centre level.

The focus groups shared a very strong concern about the monotony of activities related to their job roles and the overall lack of functional flexibility (70\%). This concern is already identified by most of the literature and is consistent as well with the quantitative results $(58 \%)$. The qualitative information highlighted the important role that job rotation has in diminishing the sense of monotony. This is an emergent theme considered neither by the literature nor by the quantitative model. Lack of job rotation and skill development seems to be a constant theme across all the call centres, irrespective of the type of service delivered (see Table 3, Appendix 1 )..

The issues identified by CSRs as a source of job dissatisfaction were related to managerial practices such as not dealing with staff concerns as they arise, inequitable decisions and lack of involvement in decision making (work environment). The most reported themes were grouped under the category of functional flexibility, which included repetition, monotony and intensity of calls. Lack of control over shifts, hours and cancelling of shifts without notice were also recurring issues (temporal flexibility). Other concerns related to themes such as monitoring (unrealistic targets and rigid scripts), HRM issues such as pay parity and incentives, lack of career opportunities and lack of training. Categories identified through the content analysis are not mutually exclusive and further clarification is needed to explain the categories and how they relate to other, which will be undertaken in the sections that follow.

Lack of job variety and lack of control over nature of duties, nature of projects was also an area of concern for CSRs (functional flexibility). Table 3, (Appendix 1) shows areas where CSRs had negative responses. The theme was categorised as control over task flexibility and can be indirectly related to a suggested solution to one of the major dislikes expressed by CSRs, in particular monotony, repetition and intensity of calls. Suggestions were made to improve managerial practices by having more staff meetings, and overall improved communication including informing staff of changes. Further suggestions that rated highly were related to improving incentives and pay structures. The remainder of the themes appear to relate to HR issues such as more ongoing training, improving career opportunities and better recognition programs. In relation to monitoring, suggestions were made to bring in more realistic targets. Some also suggested improving physical conditions such as noise levels, and improving facilities related to the built environment.

Pressure from the customer as a result of customer abuse across all case studies was only reported by outbound CSRs. Inbound CSRs felt customer pressure only when it related to dealing with calls in a set time framework which sometimes restricted the quality of service they could provide to the customer (Researchco) (calls waiting and call length pressure appeared to cause some stress).

Team leader support, fun and social environment and managerial culture, which included encouraging involvement and participation, were highlighted as the most positive aspects of job satisfaction. This is consistent with some parts of quantitative results which appeared to moderate the identified negative aspects of work. Rewards were mentioned, however what was surprising was that few responses related to the positive aspect of dealing with customers. In working environments where most tasks were devoted to servicing customers, these low positive perceptions could be problematic for CSRs and management alike.

A large focus of suggested changes to improve job satisfaction was in fact not related to monitoring and surveillance, but to improving managerial practices. The other most frequent suggestion related to lack of perceived control over temporal, numerical and functional flexibility. The only suggested changes related to employer monitoring included setting realistic targets and how targets were set to PMS. In terms of dislikes related to monitoring of work, unrealistic targets and rigid scripts also appeared to be a concern. Extrinsic and intrinsic areas of HR were raised but to a lesser extent. 


\section{Discussion}

The qualitative findings helped identify and confirm the degree and intensity of CSRs' feelings about management policy and practices. They also identified emergent themes and trends not considered by the literature previously. Table 2 illustrates the exploration of the five identified and two emergent dimensions.

\section{Insert Table 2 here}

The areas where the qualitative information was less conclusive were:

- HRM and PMS: CSRs at Superco and Legalco to some extent wanted more career development and training; other CSRs were concerned with how these were linked to the work role itself in terms of team and individual.

- Job benefits: CSRs at Superco and Legalco to some extent wanted better pay linked to years of service which was explained by their unique public service and largely unionised environments, the other call centre CSRs were more concerned with benefits linked to performance.

Other qualitative findings helped explain the following areas:

- Researchco CSRs perceived functional flexibility as less a concern because it made the job easier and less stressful, as explained by the unique culture of hiring local students to do easy work that fits in well around their study times.

- Two out of three call centre CSRs' responses (Superco and Legalco) were highly correlated amongst most dimensions. The researchers interpreted this correlation as a by-product of their perception towards equity and fairness issues as a result of the history of union participation in both organisations.

The qualitative results identified emergent themes worth considering for future research:

- Differentiation by area of work was further explained where outbound operators were concerned with customer abuse and rejection and feeling insincere about sticking to rigid scripts (Researchco). Inbound CSRs were mainly concerned with quality tensions of the customer transaction which was not rewarded and monitoring and performance practices geared towards timing, volumes, call drop-offs and call waiting.

- Differentiation by gender regarding the negative effects of unsocial hours was a concern for both males and females (Researchco). Females were less concerned with not receiving overtime payments but more with physical safety concerns of getting to and from work, as well as spill-over effects on home relationships.

- A positive aspect of all call centres was identification with company or internal teams (which has been reported rarely in the non-call-centre literature). In two there was positive identification with external customers or clients. For Legalco, this related to deriving job satisfaction through identification with the general public as it was a public service organisation. For Superco, selected clients being trade union members' superannuation and banking funds holders created a 'social reference' to helping the community or public.

Most call centre research has until recently been inconsistent in key areas. These include the use and application of reliable models and the use of complex and reliable measures that accurately assess job satisfaction of CSRs and their overall wellbeing. Other areas of concern are the methodological approaches, unit of analysis (CSRs or managers), area of work (mostly inbound operations), type of call centre functionality (in-house or outsourced), geographical context (predominantly UK or US, only a few in Australia) and nature and types of industries where the research was undertaken (restricted to mainly one organisation or to call centres in similar industries such as telecommunications or financial service industries.

Having considered these inconsistencies and shortcomings in the methodology of past research, this study set out to overcome some of them in the following ways. Firstly, it adopted consistency in terms of the unit of analysis (CSR) whilst supplementing from other sources such as management interviews and company documentation to allow for richer contextual insights.

Secondly, after an extensive literature review the researcher identified a definite gap in the use and application of consistent, reliable models and measures for researching the area of enquiry. The PJS model applied in this study was developed after careful consideration of the literature to incorporate the multi-dimensionality and complexity of measures used to study CSR job satisfaction which was strongly influenced by the approach of Rose and Wright (2005).

Thirdly, by incorporating qualitative focus groups proved invaluable in confirming the key determinants and explaining further intricate relationships between them.

Fourthly, this study chose to broaden the context to reflect the nature and diversity (types and structures) of call centres identified in the literature. The context included different call centre types (in-house, outsourced, inbound, outbound) and a diverse range of industries (public service, finance, market research, insurance, retail). Some significant findings emerged from segmentation analysis using such a broad contextual approach, in particular that 
the area of work and the type of industry were also correlated to the key determinants that predicted CSR job satisfaction.

Finally, by adopting a theoretical lens of enquiry (labour process theory and other equity theories) that views the labour process as often conflicting in nature where there is an unequal bargaining relationship of the participants and associated tensions, the research was able to question commonly held assumptions and practices, allowing for a richer analysis.

The PJS model confirmed Hypothesis 1, 2 and 3: that monitoring, flexibility and work environment are contributors to job satisfaction. This finding is consistent with the literature, although the innovative way of measuring these dimensions added another level of understanding about the way they operate within the Australian call centre context.

The qualitative results suggest that there is no evidence to validate Hypothesis 4 and 5: the association between two of the PJS model dimensions (HRM and PMS and job benefits) as contributors to job satisfaction. There is a lack of empirical research involving HRM and PMS and job benefits dimensions. Added to this, the few studies dealing with this topic tend to be confusing as a result of inconsistent ways of operationalising these concepts.

The PJS model identified a previously unknown relationship between independent variables. Two of the dimensions (flexibility and work environment) have a mediating effect on one of the independent variables (monitoring).

\section{Conclusion}

Our qualitative findings confirm that the three dimensions significant (monitoring, flexibility and work environment) are important contributors to CSR job satisfaction. These findings identified and explained the existence of complex relationships between the model's dimensions of monitoring and job satisfaction not previously reported in the literature. For instance most academic researchers considered monitoring as a negative contributor to job satisfaction. The researcher found that it has both positive and negative effects. This novel finding was the result of using a wider dimension measurement and an innovative methodological approach.

An implication for managers that surface from this study is that CSRs will exit the organisation sooner rather than later and that monetary compensation is not the quick fix solution. Managers should listen to the individual narratives and collective voice of their workers to gain a better understanding of how effective their organisations are. The front-line workers are more often than not working in isolation with the key asset of the firm, the customer. Their understanding of, and relationship with, the customer is of vital importance to the bottom line results of the business. In a consumer orientated business that could be well the point of difference to the competitive advantage of the firm.

This study has certain limitations which give rise to suggestions for future research. This study was restricted to identifying and predicting the determinants of job satisfaction for CSRs as the major outcome of the research. Linking job satisfaction to other outcomes such as customer service satisfaction and organisational profitability was not empirically tested. These relationships could be considered for future research. In addition, the information gathered related to a point in time without of course investigating changes in perceptions of job satisfaction. This limitation could be overcome by future research using a longitudinal approach.

\section{References}

ABC. (2000). The Business of Change, Four Corners, Australian Broadcasting Corporation, 28 Aug., [Online] Available: http://www.abc.net.au/4corners/archives/2000b_Monday28August2000.htm

ACA Research. (2001). Australian Call Centre Industry Study, ACA Research, Sydney.

ACA Research. (2004a). Customer Service Satisfaction Survey, ACA Research, Sydney.

ACA Research. (2008a). Australian Contact Centre Consumer Report, ACA Research, Sydney.

ACA Research. (2008b). Australia \& New Zealand Contact Centre Industry Benchmarking Report 2008, ACA Research, Sydney.

ACA Research. (2009). Australia and New Zealand Contact Centre Industry Benchmarking Report, ACA Research, Sydney.

Akerlof, GA \& Yellen, JL (eds). (1986). Efficiency Wage Models of the Labor Market. Cambridge University Press, Cambridge

Alder, GS. (1998). Ethical issues in electronic performance monitoring: A consideration of deontological and teleological perspectives. Journal of Business Ethics, vol. 17, no. 7, pp. 729-74

Alferoff, C \& Knights, D. (2001). Organizational knowledge as resistance and disciplinary mechanism in the social relations of the call centre. paper presented to 19th International Labour Process Conference, London, 26-28 March.

ASU. (2009). It's Your Call: Improving Australian Call Centres for Workers: 2009 Survey Report, Australian Services Union, Melbourne. [Online] Available: http://www.asu.asn.au/media/itsyourcall-surveyresults2009.pdf 
Bain, P \& Taylor, P. (2000). Entrapped by the "electronic panopticon"? Worker resistance in the call centre. New Technology, Work and Employment, vol. 15, no. 1, pp. 2-18

Baldry, C, Bain, P \& Taylor, P (eds). (1998). Bright Satanic Offices: Intensification, Control and Team Taylorism. Macmillan, Houndmills.

Barnes, A. (2005). The centre cannot hold': Resistance, accommodation and control in three Australian call centres, PhD thesis, School of Industrial Relations and Organisational Behaviour, Faculty of Commerce and Economics, University of New South Wales, Sydney.

Barnes, A. (2007). The construction of control: The physical environment and the development of resistance and accommodation within call centres. New Technology, Work and Employment, vol. 22, no. 3, pp. 246-59

Baudrillard, J. (1995). Simulacra and Simulation. University of Michigan Press, Ann Arbor.

Belt, V, Richardson, R \& Webster, J. (2002). Women, social skill and interactive service work in telephone call centres. New Technology, Work and Employment, vol. 17, no. 1, pp. 20-34.

Blader, SL \& Tyler, TR. (2003). What constitutes fairness in work settings? A four-component model of procedural justice. Human Resource Management Review, vol. 13, no. 1, pp. 107-26.

Braverman, H. (1974). Labor and Monopoly Capital: The Degradation of Work in the Twentieth Century. Monthly Review, New York.

Budde, A. (2002). Broadband the decade's boomer. Age, 1 May.

Callaghan, G \& Thompson, P. (2001). Edwards revisited: Technical control and call centres. Economic and Industrial Democracy, vol. 22, no. 1, pp. 13-37.

Cavana, RY, Delahaye, BL \& Sekaran, U. (2001). Applied Business Research: Qualitative and Quantitative Methods. John Wiley, Brisbane.

Chalykoff, J \& Kochan, T. (1989). Computer-aided monitoring: its influence on employee job satisfaction and turnover. Personnel Psychology, vol. 42, no. 2, pp. 807-34.

Chapman, C. (2009). Australian Communications and Media Authority. Melbourne. [Online] Available: https://www.donotcall.gov.au/

de Grip, A, Sieben, I \& van Jaarsveld, D. (2005). Employment and Industrial Relations in the Dutch Call Center Sector, Research Centre for Education and the Labour Market, Maastricht University, Maastricht

Deery, S, Iverson, R \& Walsh, J. (2002). Work relationships in telephone call centres: Understanding emotional exhaustion and employee withdrawal. Journal of Management Studies, vol. 39, no. 4, pp. 471-95.

Edwards, PK. (1990). The politics of conflict and consent: How the labor contract really works. Journal of Economic Behavior and Organization, vol. 13, no. 1, pp. 41-61.

Fernie, S \& Metcalf, D. (1998). (Not) Hanging on the Telephone: Payment Systems in the New Sweatshops, Centre for Economic Performance, London School of Economics and Political Science, London.

Folger, R. (1987). Distributive and procedural justice in the workplace. Social Justice Research, vol. 1, no. 2, pp. 143-59.

Frenkel, S, Tam, M, Korczynski, M \& Shire, K. (1998). Beyond bureaucracy? Work organization in call centres. International Journal of Human Resource Management, vol. 9, no. 6, pp. 957-79.

Hallis. (2003). Turnover and Absenteeism Survey. Hallis, Sydney.

Hannif, Z, Burgess, J \& Connell, J. (2008). Call centres and the quality of working life: Towards a research agenda. Journal of Industrial Relations, vol. 50, no. 2, pp. 271-84.

Holman, D, Batt, R \& Holtgrewe, U. (2007). The Global Call Center Report: International Perspectives on Management and Employment, [Online] Available: http://www.ilr.cornell.edu/globalcallcenter/upload/GCC-Intl-Rept-US-Version.pdf

Holman, D, Chissick, C., \& Totterdell, P. (2002). The effects of performance management on emotional labor and well-being in call centers. Motivation and Emotion, vol. 26, no. 1, pp. 57-81.

Holman, D. (2002). Employee wellbeing in call centres. Human Resource Management Journal, vol. 12, no. 4, pp. 35-50.

Hyman, J, Baldry, C, Scholarios, D \& Bunzel, D. (2003). Work-life imbalance in call centres and software development. British Journal of Industrial Relations, vol. 41, no. 2, pp. 215-39.

Kidwell, RE \& Bennett, N. (1994). Employee reactions to electronic control systems. Group and Organization Management, vol. 19, no. 2, pp. 203-19.

Kinnie, N, Hutchinson, S, Purcell, J, Rayton, B \& Swart, J. (2005). Satisfaction with HR practices and commitment to the organisation: Why one size does not fit all. Human Resource Management Journal, vol. 15, no. 4 , pp. $9-29$ 
Leventhal, GS. (1980). What should be done with equity theory? New approaches to the study of fairness in social relationships', in Gergen, K, Greensburg, M \& Wills, R. (eds) Social Exchange: Advances in Theory and Research, Plenum, New York.

Mason, D, Button, G, Lankshear, G, Coates, S \& Sharrock, W. (2002). On the poverty of apriorism: Technology, surveillance in the workplace and employee responses. Information, Communication \& Society, vol. 5, no. 4, pp. $555-72$

McManus, S. (1999). The Call of the Wild. [Online] Available: http://workers.labour.net.au/12/a

Nixon, S. (2002). Sick or not, we just can't shake the Mondayitis. Sydney Morning Herald, 10 Feb.

Origo, F \& Pagani, L. (2008). Workplace flexibility and job satisfaction: some evidence from Europe. International Journal of Manpower, vol.29, no. 6, pp. 539-566.

Paul, J \& Huws, U. (2002). How Can We Help? Good Practice in Call-Centre Employment. European Trade Union Confederation, Brussels.

Petrescu, I. A, \& Simmons, R. (2008). Human resource management practices and workers' job satisfaction. International Journal of Manpower, vol.29, no. 7, pp. 651-667.

Reilly, P. (2001). Flexibility at Work: Balancing the Interests of Employee and Employer. Gower, London.

Rose, E \& Wright, G. (2005). Satisfaction and dimensions of control among call centre customer service representatives. International Journal of Human Resource Management, vol. 16, no. 1, pp. 136-60.

Russell, B. (2008). Call centres: A decade of research. International Journal of Management Reviews, vol. 10, no. 3, pp. 195-219.

Shoebridge, N. (2000). The chase goes beyond chasing customers to building relationships. Business Review Weekly. [Online] Available: http://www.brw.com.au/content/010698/brw30.html

Taylor, P \& Bain, P. (1999). An assembly line in the head: Work and employee relations in the call centre. Industrial Relations Journal, vol. 30, no. 2, pp. 101-17.

Taylor, P, Baldry, C, Bain, P \& Ellis, V. (2003). A unique working environment: Health, sickness and absence management in UK call centres. Work, Employment and Society, vol. 17, no. 3, pp. 435-58.

Toomingas, A, Nilsson, T, Hagberg, M, Hagman, M \& Wigaeus Tornqvist, E. (2003). Symptoms and clinical findings from the musculoskeletal system among operators at a call centre in Sweden: A 10-month follow-up study. International Journal of Occupational Safety and Ergonomics, vol. 9, no. 4, pp. 405-18.

Wallace, C, Eagleson, G \& Waldersee, R. (2000). The sacrificial HR strategy in call centres. International Journal of Service Industry Management, vol. 11, no. 2, pp. 174-84.

Walsh, J \& Deery, S. (2006). Refashioning organizational boundaries: Outsourcing customer service work. Journal of Management Studies, vol. 43, no. 3, pp. 557-82.

Yin, RK. (2003). Case Study Research: Design and Methods, 3rd edn, Sage. Thousand Oaks, California.

Table 1. Guidelines for focus group discussions

The broad topics of discussion for the focus groups were:

- Monitoring and surveillance in call centres

- Examples of monitoring and surveillance at work

- Their perception of the effect of monitoring and surveillance on their job satisfaction

- Their perceptions of workplace flexibility, work environment; organizational culture; relationship with management and supervisor; relationship with customer; job benefits; HRM and PMS

- Their likes, dislikes and suggested changes to work practices in call centres to improve job satisfaction

- What participants consider to be the most important contributors to job satisfaction

- Any further suggestions for the study 
Table 2. Cross-case analysis findings of dimensions and CSR perceptions

\begin{tabular}{|l|c|c|c|}
\hline & \multicolumn{3}{|c|}{ Company } \\
\hline Dimensions & Researchco & Superco & Legalco \\
\hline $\begin{array}{l}\text { 1. a) Monitoring of work related matters (technological } \\
\text { pressure and customer pressure) }\end{array}$ & - & + & + \\
b) Personal privacy over non-work-related matters & - & + & + \\
\hline $\begin{array}{l}\text { 2. a) Employee control over work environment } \\
\text { b) Culture }\end{array}$ & - & + & + \\
\hline 3. a) Flexibility numerical, temporal flexibility & - & + & + \\
b) Task functional flexibility repetition and monotony & + & - & - \\
\hline 4. Performance management and HRM factors & - & - & - \\
5. Job benefits & - & - & - \\
\hline 6. Built environment & - & + & + \\
\hline 7. Emotional pressure from customer & - & + & + \\
\hline
\end{tabular}

( $+=$ positive CSR attitude to dimension), ( $-=$ negative CSR attitude to dimension).

\section{Appendix 1: Focus group findings: Negative CSR responses}

Table 3. Focus group findings: Negative CSR responses

\begin{tabular}{|c|c|c|c|c|c|c|}
\hline $\begin{array}{l}\text { Number of } \\
\text { responses } \\
\mathrm{R}=\text { Researchco }=12 \\
\mathrm{~S}=\text { Superco } \quad=12 \\
\mathrm{~L}=\text { Legalco } \quad=12 \\
\mathrm{~T}=\text { All centres }=36\end{array}$ & $\begin{array}{l}\text { Coded } \\
\text { themes (by } \\
\text { dimension) }\end{array}$ & $\begin{array}{l}\text { Number } \\
\text { of } \\
\text { incidences }\end{array}$ & $\begin{array}{l}\text { Literature } \\
\text { Consistent } \\
\text { similar } \\
\text { context CSC } \\
\text { Consistent } \\
\text { dissimilar } \\
\text { taxonomy } \\
\text { CDT }\end{array}$ & $\begin{array}{l}\text { Quantitative } \\
\text { findings } \\
\text { Yes } \\
\text { No }\end{array}$ & $\begin{array}{l}\text { Emergent } \\
\text { themes } \\
\text { E }\end{array}$ & Keywords and description of code \\
\hline $\begin{array}{l}\text { R } \\
\text { S } \\
\text { L } \\
\text { Total }\end{array}$ & $\begin{array}{l}\text { Functional } \\
\text { flexibility }\end{array}$ & $\begin{array}{r}10 \\
3 \\
2 \\
15\end{array}$ & $\mathrm{CSC}$ & Yes & $\mathrm{E}$ & $\begin{array}{l}\text { Monotony, repetitive work, } \\
\text { intensity, large volumes of calls, } \\
\text { rigid scripts (six Researchco outbound } \\
\text { CSRs only) } \\
\text { Differentiation between inbound } \\
\text { concerns of intensity, repetitiveness } \\
\text { and monotony. Outbound concerned } \\
\text { with rigidity of scripts }\end{array}$ \\
\hline $\begin{array}{l}\text { R } \\
\text { S } \\
\text { L } \\
\text { Total }\end{array}$ & $\begin{array}{l}\text { Work } \\
\text { environment }\end{array}$ & $\begin{array}{r}10 \\
2 \\
0 \\
17\end{array}$ & $\begin{array}{l}\operatorname{CSC} \\
\operatorname{CSC}\end{array}$ & $\begin{array}{l}\text { Yes } \\
\text { No }\end{array}$ & & $\begin{array}{l}\text { Poor management practices } \\
\text { including: unfair decisions by } \\
\text { management, lack of Involvement of } \\
\text { CSRs in decision making } \\
\text { Lack of staff meeting meetings to } \\
\text { discuss work issues } \\
\text { Abusive managers, poor treatment } \\
\text { and nepotism regarding promotions } \\
\text { and pay rises }\end{array}$ \\
\hline $\begin{array}{l}\text { R } \\
\text { S } \\
\text { L } \\
\text { Total }\end{array}$ & $\begin{array}{l}\text { Temporal } \\
\text { flexibility }\end{array}$ & $\begin{array}{l}8 \\
0 \\
0 \\
8\end{array}$ & $\begin{array}{l}\text { CSC } \\
\text { CDT }\end{array}$ & Yes & E & $\begin{array}{l}\text { Lack of control of hours, shifts } \\
\text { Shifting agents from inbound to } \\
\text { outbound without notice and } \\
\text { compensation and no training. Breaks } \\
\text { not long enough } \\
\text { Unsocial hours Differentiation on } \\
\text { gender (link to lack of personal safety } \\
\text { to and from work - female } \\
\text { Male CSRs all centres concerns re: } \\
\text { lack of penalty rates for unsocial } \\
\text { hours }\end{array}$ \\
\hline $\begin{array}{l}R \\
\text { S } \\
\text { L } \\
\text { Total }\end{array}$ & Job benefits & $\begin{array}{l}0 \\
3 \\
3 \\
6 \\
\end{array}$ & CSC & Yes & & $\begin{array}{l}\text { Pay parity and lack of incentives. Lack } \\
\text { of pay rises }\end{array}$ \\
\hline $\begin{array}{l} \\
S \\
L\end{array}$ & $\begin{array}{l}\text { Other issues } \\
\text { Emotional } \\
\text { pressure from }\end{array}$ & $\begin{array}{l}0 \\
2 \\
0\end{array}$ & CDT & No & & $\begin{array}{l}\text { Customer rejections and abuse (verbal } \\
\text { and telephone slamming) } \\
\text { (Outbound CSRs or those involved in }\end{array}$ \\
\hline
\end{tabular}




\begin{tabular}{|c|c|c|c|c|c|c|}
\hline Total & customer & 2 & & & $E$ & $\begin{array}{l}\text { sales outcomes only) } \\
\text { Differentiated by role outbound only. } \\
\text { Inbound did not raise this as an area } \\
\text { of concern }\end{array}$ \\
\hline $\begin{array}{l}\text { R } \\
\text { S } \\
\text { L } \\
\text { Total }\end{array}$ & $\begin{array}{l}\text { (HRM) } \\
\text { (HRM) } \\
\text { HRM and PMS }\end{array}$ & $\begin{array}{l}4 \\
2 \\
6 \\
12\end{array}$ & $\begin{array}{l}\mathrm{CSC} \\
\mathrm{CSC} \\
\mathrm{CSC}\end{array}$ & $\begin{array}{l}\text { Yes } \\
\text { Yes } \\
\text { No }\end{array}$ & & $\begin{array}{l}\text { Lack of career opportunities } \\
\text { No ongoing training - only training } \\
\text { devoted to new recruits and not for } \\
\text { developing permanent staff (Legalco) }\end{array}$ \\
\hline $\begin{array}{l}\mathrm{R} \\
\mathrm{S} \\
\mathrm{L} \\
\text { Total }\end{array}$ & Other issues & $\begin{array}{l}5 \\
2 \\
0 \\
7\end{array}$ & $\operatorname{CSC}$ & No & & $\begin{array}{l}\text { Isolation from team (no time to } \\
\text { socialise or discuss work matters on } \\
\text { job), only time to socialise if you } \\
\text { attend out of hours functions }\end{array}$ \\
\hline $\begin{array}{l}R \\
S \\
L \\
\text { Total }\end{array}$ & Monitoring & $\begin{array}{r}0 \\
0 \\
4 \\
4\end{array}$ & $\begin{array}{l}\text { CSC } \\
\text { CDT }\end{array}$ & Yes & $E$ & $\begin{array}{l}\text { Constant pressure the number of calls } \\
\text { waiting prompt on your computer } \\
\text { screen. Time pressure and associated } \\
\text { anxiety. Role conflict torn between } \\
\text { providing quality customer service or } \\
\text { just answering quantity of calls } \\
\text { Differentiation inbound compared to } \\
\text { outbound. Outbound concerned less } \\
\text { with overall monitoring, unrealistic } \\
\text { targets, rigid scripts. Inbound more } \\
\text { concerned with excessive and } \\
\text { intensity on quantity criteria of } \\
\text { monitoring }\end{array}$ \\
\hline $\begin{array}{l}R \\
S \\
L \\
\text { Total }\end{array}$ & $\begin{array}{l}\text { Personal } \\
\text { privacy }\end{array}$ & $\begin{array}{l}5 \\
0 \\
0 \\
5\end{array}$ & CDT & Yes & & $\begin{array}{l}\text { Policies are in place to allow facilities } \\
\text { and time to attend to personal } \\
\text { matters during work } \\
\text { Time pressures don't allow this } \\
\text { Management have strict policies } \\
\text { against this and punish this behaviour } \\
\text { Research co team leaders always } \\
\text { listening in }\end{array}$ \\
\hline
\end{tabular}

Source: CSR coded responses derived focus groups 'what like least about working in call centre'. N=36

\section{Appendix 2: Focus group findings: Positive CSR responses}

Table 4. Focus group findings: Positive CSR responses

\begin{tabular}{|c|c|c|c|c|c|c|}
\hline $\begin{array}{l}\text { Call centre } \\
R= \\
\text { Researchco } \\
S=\text { Superco } \\
\text { L= Legalco } \\
T=\text { All centres }\end{array}$ & $\begin{array}{l}\text { Coded } \\
\text { themes }\end{array}$ & $\begin{array}{l}\text { Number of } \\
\text { incidences }\end{array}$ & $\begin{array}{l}\text { Literature } \\
\text { Consistent } \\
\text { similar } \\
\text { context } \\
\text { CSC } \\
\text { Consistent } \\
\text { dissimilar } \\
\text { taxonomy }\end{array}$ & $\begin{array}{l}\text { Quantitative } \\
\text { findings } \\
\text { Yes } \\
\text { No }\end{array}$ & $\begin{array}{l}\text { Emergent } \\
\text { themes } \\
\text { E }\end{array}$ & Keywords and description of code \\
\hline $\begin{array}{l}\text { R } \\
\text { S } \\
\text { L } \\
\text { Total }\end{array}$ & $\begin{array}{l}\text { Identification } \\
\text { with } \\
\text { 1)customer } \\
\text { 2)organisation } \\
\text { 3) team }\end{array}$ & $\begin{array}{l}8 \\
6 \\
6 \\
20\end{array}$ & $\begin{array}{l}\text { CDT } \\
\text { CDT } \\
\text { CSC } \\
\text { CDT }\end{array}$ & $\begin{array}{l}\text { No } \\
\text { No } \\
\text { No } \\
\text { No } \\
\text { No }\end{array}$ & E & $\begin{array}{l}\text { Culture aligned to helping client (Legalco = } \\
6 \text { good Samaritan role) } \\
\text { Culture aligned well to assisting members } \\
\text { (clients) Superco }=6 \\
\text { Team culture (Researchco friendly student } \\
\text { workers }=8 \text { ) } \\
\text { Overall positive identification with culture } \\
\text { aspects }\end{array}$ \\
\hline $\begin{array}{l}\text { R } \\
\text { S } \\
\text { L } \\
\text { Total }\end{array}$ & $\begin{array}{l}\text { Management } \\
\text { and team } \\
\text { leader support }\end{array}$ & $\begin{array}{l}2 \\
6 \\
5 \\
13\end{array}$ & & & & $\begin{array}{l}\text { Superco (management and team leaders } \\
\text { encourage input and participation) } \\
\text { Legalco (management and team leaders } \\
\text { encourage input and participation) } \\
\text { Other team leaders are supportive }\end{array}$ \\
\hline $\begin{array}{l}\text { R } \\
\text { S } \\
\text { L } \\
\text { Total }\end{array}$ & Casual dress & $\begin{array}{l}3 \\
0 \\
0 \\
3\end{array}$ & $\begin{array}{l}\text { CDT } \\
\text { CDT }\end{array}$ & No & $E$ & Casual dress code aligned to internal teams \\
\hline
\end{tabular}




\begin{tabular}{|c|c|c|c|c|c|c|}
\hline $\begin{array}{l}\text { R } \\
\text { S } \\
\text { L } \\
\text { Total }\end{array}$ & $\begin{array}{l}\text { Pay and } \\
\text { benefits } \\
\text { Non-monetary } \\
\text { rewards }\end{array}$ & $\begin{array}{c}10 \\
0 \\
0 \\
10\end{array}$ & CDT & $\begin{array}{l}\text { Yes } \\
\text { Yes }\end{array}$ & & $\begin{array}{l}\text { Realistic targets (Researchco) no pressure } \\
\text { easy work for average pay fits in well with } \\
\text { study commitments } \\
\text { Good conditions }\end{array}$ \\
\hline $\begin{array}{l}\text { R } \\
\text { S } \\
\text { L } \\
\text { Total }\end{array}$ & $\begin{array}{l}\text { Customer } \\
\text { contact }\end{array}$ & $\begin{array}{c}3 \\
0 \\
0 \\
3\end{array}$ & $\operatorname{CSC}$ & Yes & & Customer satisfaction from job \\
\hline $\begin{array}{l}R \\
S \\
L \\
\text { Total }\end{array}$ & $\begin{array}{l}\text { Temporal } \\
\text { flexibility } \\
\text { Choosing shifts } \\
\text { To suit }\end{array}$ & $\begin{array}{l}8 \\
0 \\
0 \\
8\end{array}$ & $\begin{array}{l}\text { CDT } \\
\text { CDT }\end{array}$ & & & $\begin{array}{l}\text { Allow to pick shifts around university } \\
\text { studies (Researchco }=8 \text { ) }\end{array}$ \\
\hline $\begin{array}{l}\text { R } \\
\text { S } \\
\text { L } \\
\text { Total }\end{array}$ & $\begin{array}{l}\text { Monitoring } \\
\text { as safeguard }\end{array}$ & $\begin{array}{l}0 \\
3 \\
3 \\
3\end{array}$ & $\begin{array}{l}\text { CDT } \\
\text { CSC }\end{array}$ & $\begin{array}{l}\text { No } \\
\text { Yes } \\
\text { No }\end{array}$ & $\mathrm{E}$ & $\begin{array}{l}\text { Positive aspects of monitoring include } \\
\text { ensuring work equitability (i.e. prevent some } \\
\text { staff from slacking off) } \\
\text { Ambivalence or acceptance that } \\
\text { management have a right to monitor work } \\
\text { performance and quality assurance. Call } \\
\text { monitoring may diffuse customer abuse and } \\
\text { hostility when customers are informed that } \\
\text { calls would be monitored for quality } \\
\text { purposes (outbound CSRs only) }\end{array}$ \\
\hline
\end{tabular}

Source: CSR coded responses of focus groups 'what like most about working in call centre'. N=36 (Note: there can be more than one response from individuals).

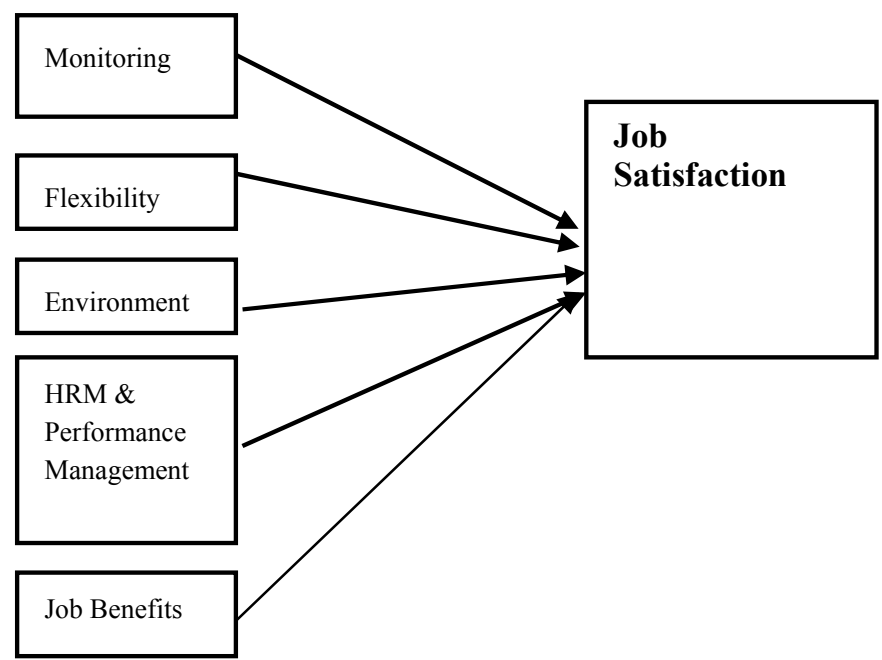

Figure 1. Conceptual framework: Predictors of job satisfaction (CSRs) model 


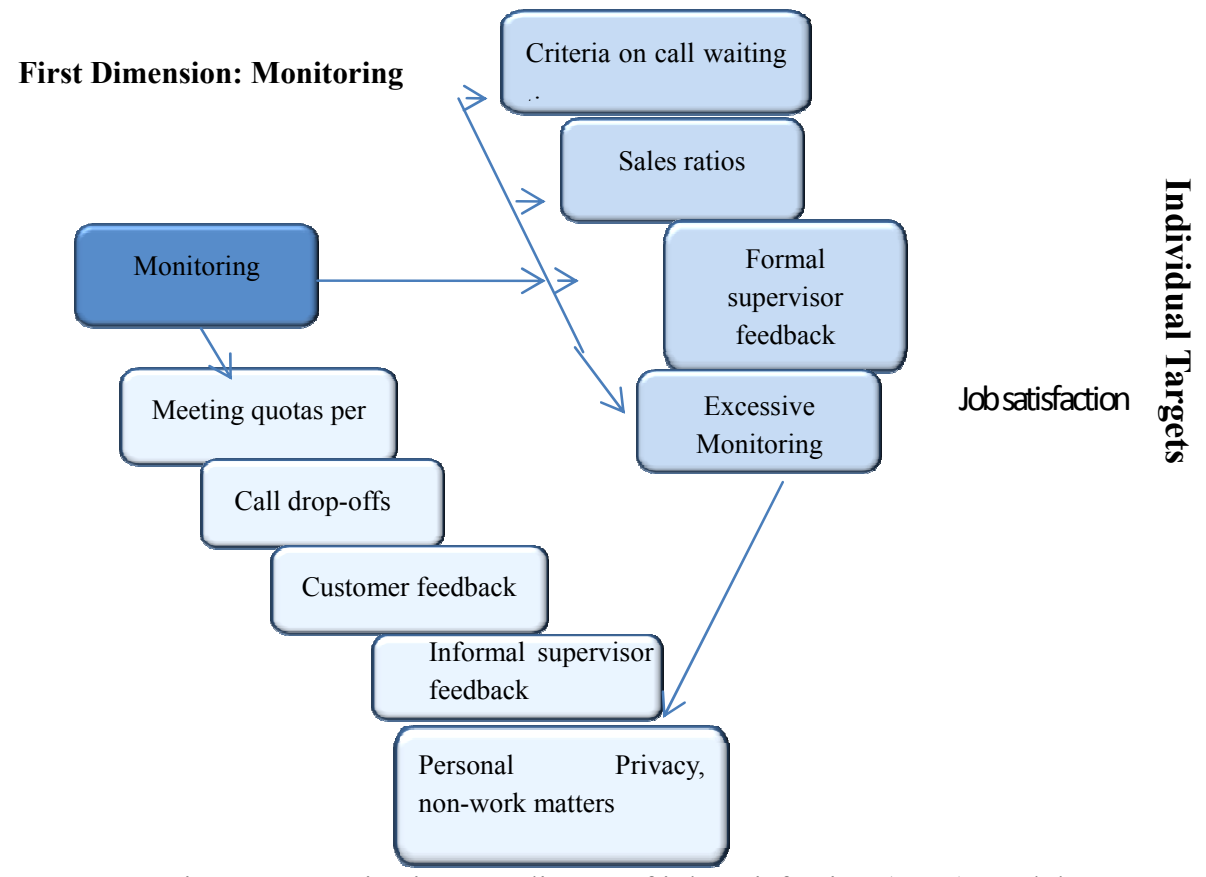

Figure 2. Monitoring: Predictors of job satisfaction (CSR) model

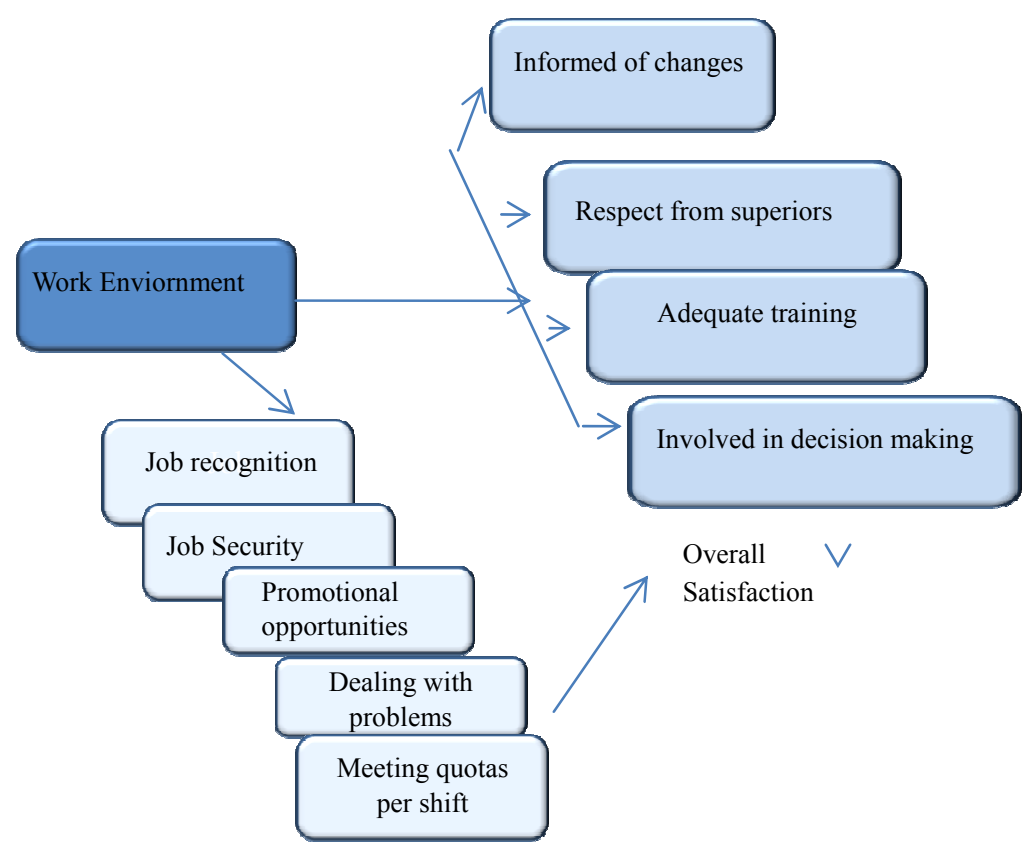

Figure 3. Work environment: Predictors of job satisfaction (CSR) model 
Third Dimension: Flexibility

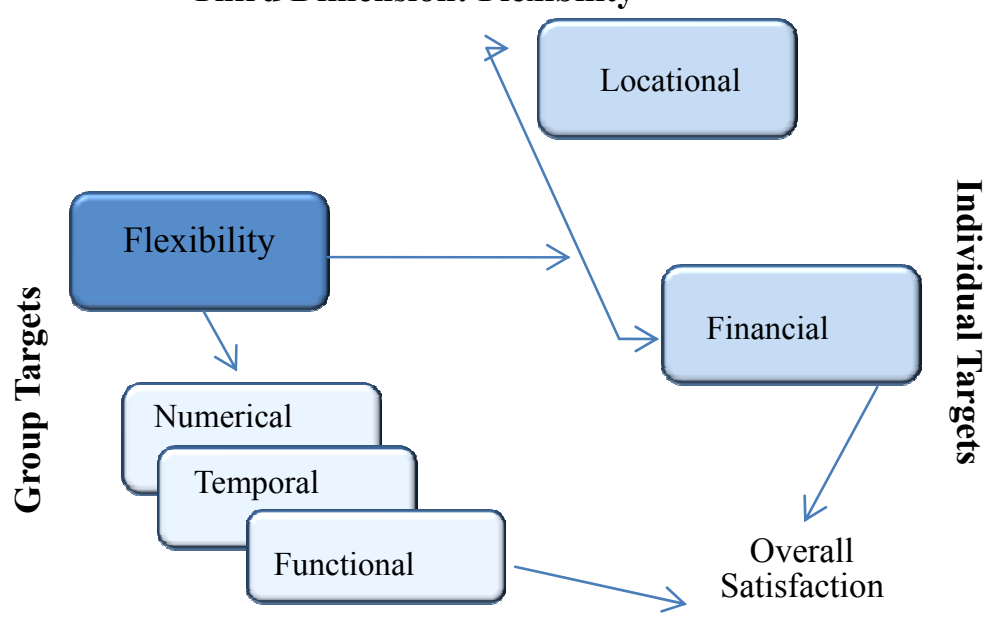

Figure 4. Flexibility: Predictors of job satisfaction (CSR) model

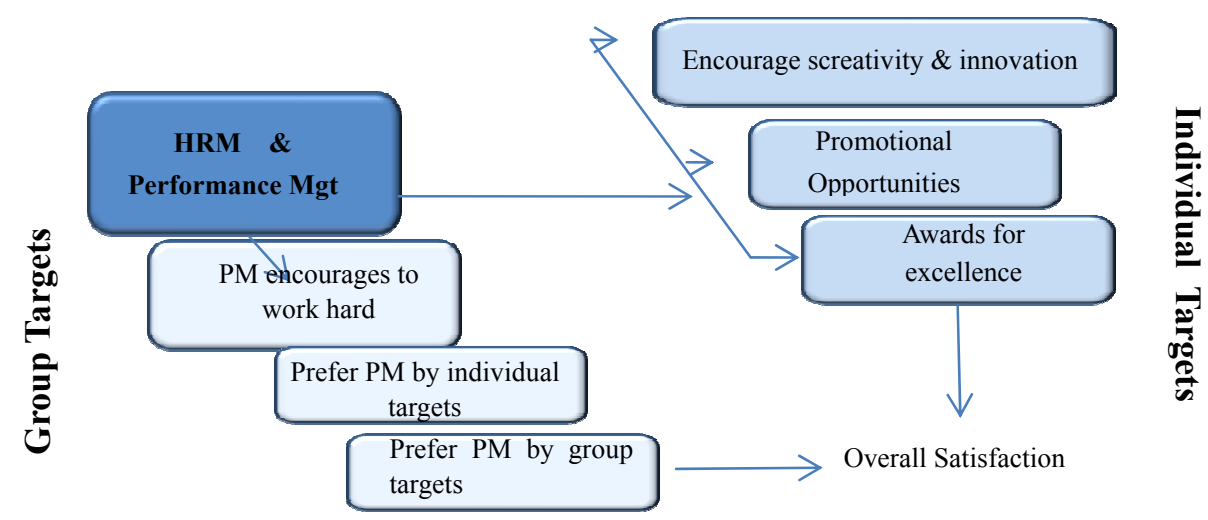

Figure 5. HRM and PMS: Predictors of job satisfaction (CSRs) model

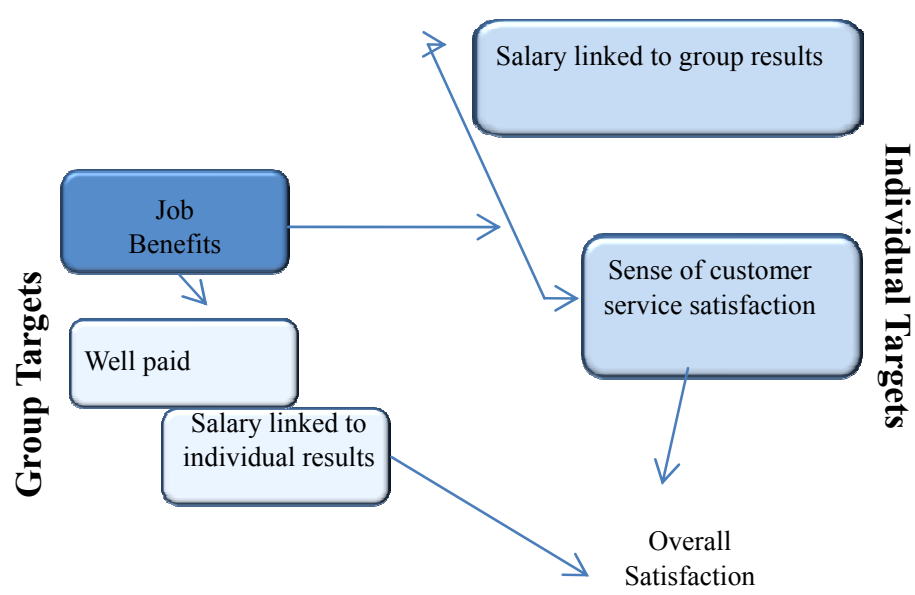

Figure 6. Job benefits: Predictors of job satisfaction (CSRs) model 